\title{
Randomised controlled trial of the effect of evidence based information on women's willingness to participate in cervical cancer screening
}

\author{
P Adab, T Marshall, A Rouse, B Randhawa, H Sangha, N Bhangoo
}

J Epidemiol Community Health 2003;57:589-593

See end of article for authors' affiliations

Correspondence to: Dr P Adab, Department of Public Health and

Epidemiology, University of Birmingham, Edgbaston, Birmingham B15 2TT, UK; p.adab@bham.ac.uk

Accepted for publication 5 February 2003

\begin{abstract}
Study objectives: To assess whether providing women with additional information on the pros and cons of screening, compared with information currently offered by the NHS, affects their intention to attend for screening.

Design: Randomised controlled trial. Participants were randomly assigned to receive either the control, (based on an NHS Cervical Screening Programme leaflet currently used), or the intervention leaflet (containing additional information on risks and uncertainties).

Setting: Three general practices in Birmingham.

Participants: 300 women aged 20 to 64 attending the practices during a one month period.

Main outcome measures: Intention to attend for screening.

Main results: 283 women (94.3\%) completed the study. Fewer women in the intervention (79\%) than the control group (88\%) expressed intention to have screening after reading the information leaflet (difference between groups $9.2 \%, 95 \%$ confidence intervals (CI) $3.2 \%$ to $21.7 \%$ ). The crude odds ratio $(\mathrm{OR})$ and $95 \% \mathrm{Cl}$ was 0.50 (0.26 to 0.97$)$. After adjusting for other factors, the trend persisted (OR $0.60,95 \% \mathrm{Cl} 0.28$ to 1.29$)$. Having a previous Pap smear was the only significant predictor of intention to have screening (adjusted $\mathrm{OR} 2.54,95 \% \mathrm{Cl} 1.03$ to 6.21 ). Subgroup analysis showed no intervention effect in intended uptake between women at higher and lower risk of cervical cancer $(p=0.59)$. Conclusions: Providing women with evidence based information on the risks, uncertainties, and the benefits of screening, is likely to deter some, but not differentially those at higher risk.
\end{abstract}

A bout 3.8 million women in England have a smear test each year, ${ }^{1}$ at a cost to the NHS of $£ 34$ per person. ${ }^{2}$ Most researchers agree that organised population screening has contributed to a reduction in the incidence of invasive cervical cancer. ${ }^{3}$ An estimated 800 (England) to 1300 (England and Wales) new cases per year are prevented as a result of screening. ${ }^{35}$ However, this has been achieved at high cost. The number of abnormalities detected and referrals for colposcopy far exceed the number of cases prevented. ${ }^{6}$ Over a lifetime, a woman with average risk for cervical cancer (less than one in 10000 ), and who has seven smear tests, has a one in two chance of having an abnormal result, ${ }^{16}$ and one in five chance of having colposcopy. ${ }^{6}$ Furthermore, test sensitivity is not high and false negative rates can be has high as $25 \%$.

Unfortunately women often do not understand the risks and uncertainties ${ }^{8}$ and are less aware of the limitations than the benefits associated with screening. ${ }^{9}$ However, dealing with this was not an NHS priority in the past. ${ }^{9}$ Leaflets are important sources of patient information ${ }^{10}$ and these are usually sent to all women with their first invitation for cervical screening. However, the main aim of such information is to maximise uptake and therefore it generally over-emphasises the benefits, and rarely mentions the risks. ${ }^{11}$ This prevents women from making an informed choice, and may contribute to accusations of negligence when screening has "failed". ${ }^{12}$

More recently the General Medical Council in the UK (GMC) issued guidance on informed choice for all medical procedures, including screening ${ }^{13}$ and emphasised that patients should be given information on risks, uncertainties, and costs to them of participating. Several researchers ${ }^{14-17}$ have highlighted the importance of this in cervical screening, but for various reasons reluctance persists. Paternalistic attitudes promote the idea that patients cannot cope with uncertainties, ${ }^{10}$ and such communication is not in their best interest, as it may reduce attendance. Indeed, additional information can sometimes heighten risk perception, ${ }^{18}$ promote decisional conflict, and is not always welcome by patients. ${ }^{19}$ Secondly, within the NHS, professionals are rewarded for achieving high screening coverage. ${ }^{11}{ }^{20}$ It is not in their interest to give women information that may discourage them from attending. ${ }^{21}$ A less cynical argument is that if a high proportion of women are discouraged from attending, the programme would fail to have a significant population impact.

All these arguments assume that providing more information will affect screening uptake, but to our knowledge, no study has previously assessed this. Our main objective was to estimate the effect on expressed uptake, of providing more information on the risks and uncertainties associated with cervical screening, compared with the information currently provided by the NHS. ${ }^{22}$ We also examined the effects of any difference in expressed uptake between women at higher and lower risk for cervical cancer.

\section{METHODS}

\section{Study design and population}

This was a randomised controlled trial undertaken at three general practices in Birmingham. We invited women between the ages of 20 and 64 attending the practices to participate. Permission for the trial was obtained from South Birmingham Research Ethics Committee and all participants were provided with information on the study before being asked to give written consent.

\section{Intervention}

We devised two types of information leaflet. The control leaflet was based on one produced by the NHSCSP. It included information on the nature and purpose of screening, what the 
test involves, choice of venue, how results will be obtained, and possible reasons for further tests.

The intervention leaflet, in addition to the above, contained information on the absolute average individual risk for cervical cancer, likelihood of positive findings, the possibility of false positive/negative results, the uncertainties attached to the screening process, the absolute benefit associated with screening and the cost of the process to the NHS (appendix, available on the journal web site www.jech.com/ supplemental).

As the NHS cervical screening programme is well established, and coverage is linked to practice performance measures and to GP remuneration, all reference to "cervical" cancer, "cervical" screening, or "smear test" were removed from the leaflets. This was to gain cooperation and minimise disruption to participating practices. Nevertheless, all the facts presented were related to cervical screening. Thus the intervention leaflet explained that screening prevented the onset of this particular cancer. In addition, it explained the burden of cancer (10/10 000 mortality), the absolute benefit of screening (reduced risk to $1 / 10000$ ), risk of false positive (2000 recalled for every one woman with cancer) and false negative (around 10\%). This information was all based on data from the cervical screening programme in the UK.

\section{Protocol and random assignment}

We developed a structured questionnaire that was previously piloted on 20 women. One of us (PA) prepared a computer generated list of random numbers, which was used to sequence questionnaires to contain either the control or intervention leaflet. Three of us (BR, HS, and NB) visited participating practices on several occasions between April and May 2001 and distributed questionnaires in random order. Participants, who were blind as to which arm they were allocated to, were asked to leave completed questionnaires with the reception before leaving the practice.

\section{Outcome measures}

The main outcome measure was expressed willingness to have the "study screening test". This is an accepted outcome measure, ${ }^{23} 24$ having also been used in previous studies.

\section{Other measures}

We collected information on sociodemographic factors, health related behaviours, and whether they had any family or close friends with cancer. Social class of respondents was determined based on the occupation of the main wage earner in the household ( social class I=highest, and V=lowest). In addition, we developed a risk score for cervical cancer, based on the woman's age, social class, and smoking status. Those with scores below the median were labelled as "lower risk", and the rest as "higher risk".

\section{Sample size}

The five year uptake of cervical screening in the UK is estimated to be around $80 \%{ }^{1}$ We calculated that in order to detect a difference in intended uptake between groups of $15 \%$ or more with $95 \%$ confidence and $80 \%$ power, a minimal sample size of 276 ( 138 in each group) was required.

\section{Statistical analysis}

We compared intended uptake of the study screening test among the intervention and control groups. Bivariate analysis, using $\chi^{2}$ for binary categorical variable, $\chi^{2}$ for trend for ordinal variables and $t$ test for linear variables, was used to compare intended screening in relation to other factors. Any characteristic that was associated with intended uptake at a level of significance of $10 \%$ or less was entered in a logistic regression model (using the "enter" method), to obtain an adjusted odds ratio for the intervention compared with the control group.

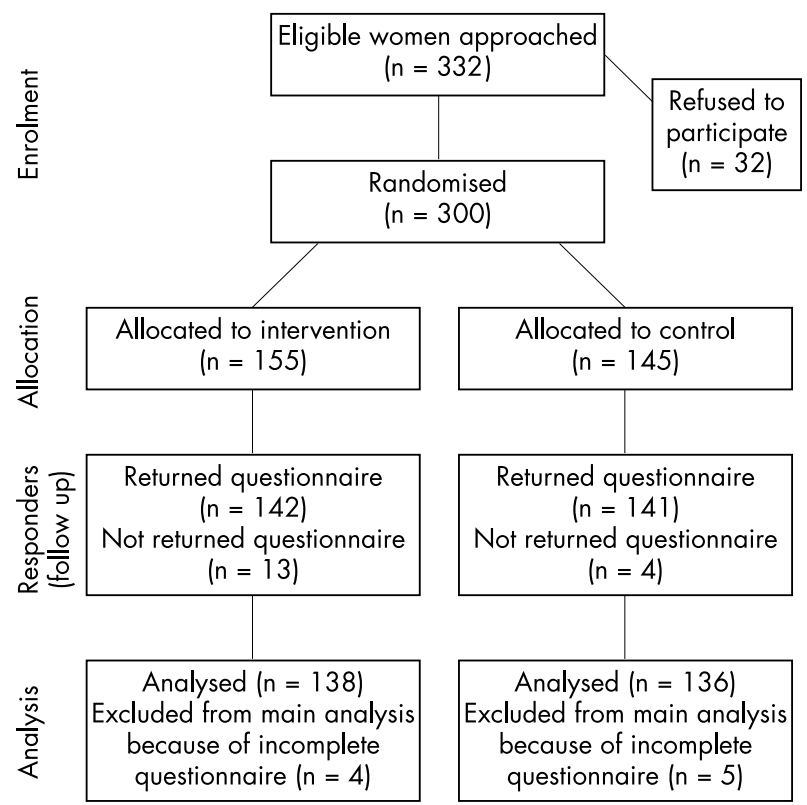

Figure 1 Flowchart of recruitment and participants in the trial.

Subgroup analysis was performed to compare women at higher and lower risk of cervical cancer. All statistical analyses were performed with SPSS (version 10).

\section{RESULTS}

\section{Participant flow and follow up}

About $10 \%$ of women approached refused to participate, and were not given a questionnaire. Among 300 women who gave consent, 283 (94.3\%) returned their questionnaires (fig l).

\section{General description}

The mean age of responders was 39.4 years, and a sizeable minority (17.3\%) were non-white, reflecting the population in Birmingham and the practices participating in the study. Control and intervention groups were similar in all respects, except for a significantly higher proportion of non-white women in the intervention compared with the control group (table 1).

\section{Intended uptake of screening test}

Most responders (229 of 274, 83.6\%) expressed their willingness to attend for the study screening test. However, those in the intervention group were significantly less likely to want the test $(109$ of $138,79.0 \%)$ compared with the control group ( 120 of 136, 88.2\%) (difference between groups 9.2\% (95\% CI 3 to 21.7 ), unadjusted OR 0.50 (95\% CI 0.26 to 0.97 ) $p=0.039$ ).

A high proportion of responders (257 of $277,92.8 \%$ ) had attended for a Pap smear in the past; $72.9 \%$ within three years, and $82.3 \%$ within the past five years. None of the sociodemographic or behavioural factors we inquired about were significantly associated with having had a Pap smear within the past five years. However, women who had been previously screened were significantly more likely to say they would attend for the study screening test (OR 2.3,95\% CI 1.1 to 4.8 ). Other factors associated with intention to take up the study screening test included attending regularly for dental check ups (OR 3.19, 95\% CI 1.52 to 6.73) and having close friends or family with cancer (OR 1.98, 95\% CI 0.99 to 3.96). After adjusting for these variables, exposure to the intervention leaflet was still associated with reduced expressed willingness to have the study screening test, though this was no longer statistically significant (table 2). Having had a Pap smear in the past was a significant predictor of intention to have screening, whereas cervical cancer risk was not. Repeating the 
Table 1 Comparison of intervention and control groups at baseline (values are numbers and (percentages) unless otherwise stated)

\begin{tabular}{|c|c|c|}
\hline Participant characteristics & $\begin{array}{l}\text { Control } \\
(n=141)\end{array}$ & $\begin{array}{l}\text { Intervention } \\
(n=142)\end{array}$ \\
\hline \multicolumn{3}{|l|}{ Sociodemographic characteristics } \\
\hline Age $^{*}$ & $39.3(20-64)$ & $39.5(20-64)$ \\
\hline \multicolumn{3}{|l|}{ Marital status } \\
\hline Single/divorced/widowed & $54(39.1)$ & $50(36.0)$ \\
\hline Married/living with partner & $84(60.9)$ & 89 (64.0) \\
\hline \multicolumn{3}{|l|}{ Social class } \\
\hline I and II & $35(31.3)$ & $37(32.7)$ \\
\hline III & $58(51.8)$ & $60(53.1)$ \\
\hline IV and V & 19 (17.0) & $16(14.2)$ \\
\hline \multicolumn{3}{|l|}{ Ethnicity } \\
\hline White & $118(87.4)$ & 107 (77.0) \\
\hline Non-white & $17(12.6)$ & $32(23.0)$ \\
\hline \multicolumn{3}{|l|}{$\begin{array}{l}\text { Personal contact with someone with cancer } \\
\text { Having family or close friends with cancer }\end{array}$} \\
\hline Yes & $64(45.4)$ & $57(40.1)$ \\
\hline No & $77(54.6)$ & 85 (59.9) \\
\hline \multicolumn{3}{|l|}{ Health related behaviour } \\
\hline \multicolumn{3}{|l|}{ Pap smear within past five years } \\
\hline Yes & 110 (79.7) & $118(84.9)$ \\
\hline No & $28(20.3)$ & $21(15.1)$ \\
\hline \multicolumn{3}{|l|}{ Make regular visits to dentist } \\
\hline Yes & $120(85.7)$ & $117(83.6)$ \\
\hline No & $20(14.3)$ & $23(16.4)$ \\
\hline \multicolumn{3}{|l|}{ Smoking status } \\
\hline Never smoker & $68(48.2)$ & $70(49.3)$ \\
\hline Former smoker & $36(25.5)$ & $41(28.9)$ \\
\hline Current smoker & $37(26.2)$ & $31(21.8)$ \\
\hline \multicolumn{3}{|l|}{ Risk for cervical cancer } \\
\hline Risk score* (based on age, social class, and smoking status) & $5.5(3-9)$ & $5.4(3-9)$ \\
\hline
\end{tabular}

Table 2 Results of logistic regression model assessing the factors associated with women's expressed intention to have the study screening test

\begin{tabular}{llll}
\hline Intention to have study screening test & Adjusted OR & $(95 \% \mathrm{Cl})$ & Level of significance \\
\hline Exposure to intervention & 0.60 & $(0.28$ to 1.29$)$ & 0.191 \\
Previous Pap smear within past five years & 2.54 & $(1.03$ to 6.21$)$ & 0.042 \\
Regular dentist attendee & 2.26 & $(0.96$ to 5.29$)$ & 0.062 \\
Having family/friends with cancer & 1.99 & $(0.89$ to 4.48$)$ & 0.096 \\
Higher risk for cervical cancer & 0.94 & $(0.44$ to 2.02$)$ & 0.871 \\
\hline
\end{tabular}

logistic regression model with an interaction term between the intervention effect and level of risk showed no significant interaction $(p=0.59)$.

We also found that $87.6 \%$ (240 of 274) thought the government should set up a national screening programme, including $59 \%(n=26)$ of those who did not want to attend themselves. Those in the intervention group were less likely to think such a programme should be implemented compared with the control group, though the difference was not statistically significant.

\section{DISCUSSION}

We found that providing women with more information about the risks and uncertainties of screening, as well as the benefits, resulted in a small reduction in expressed willingness to attend for screening. However, even among women who were given more information, intended screening rates were nearly $80 \%$.

\section{Strengths and weaknesses of the study}

To our knowledge this is the first trial to assess the effect of giving evidence based information on women's expressed willingness to attend for a screening test that is already well established. The five year coverage for cervical screening within the study population was the same as that for
Birmingham generally $(80.6 \%),{ }^{1}$ and this, together with the high response rate suggests that they were fairly representative of the target group.

We tried to blind participants to what the study test was, and the condition to which screening referred. The aim was to limit interference with their prior understanding and beliefs about the Pap smear, and to gain cooperation from participating practices. On the other hand, decisions may have differed had women known that we were referring to cervical screening. As in some other studies, ${ }^{23}{ }^{24}$ our principal outcome was expressed willingness to have screening, which may differ from actual attendance. While actual uptake would be the ideal outcome measure, time and resource limitations prevented us from using this. This may partly explain the higher proportion of women who said they would attend in the control group, compared with those that currently have Pap smears. We could not compare knowledge between the two groups, and cannot directly infer that women in the intervention group had a better understanding of the pros and cons of the test. However, evidence suggests that people generally understand absolute risks (as used in the intervention leaflet) better than relative risks. ${ }^{25}$ Also, our sample size did not allow sufficient power to detect a difference in intended uptake of less than $15 \%$ between groups. 


\section{Key points}

- Cervical screening can cause harm as well as benefit.

- Despite guidance from the GMC and others to obtain informed consent before screening, the risks and uncertainties are not well communicated to women.

- There are fears that giving women additional evidence based information on screening will reduce uptake and undermine the national programme.

- We found that providing additional, more balanced information about screening does reduce willingness to attend for screening, but not considerably so.

- The findings should counteract the reluctance among some to provide women with more information.

\section{Policy implications}

- Ethical and professional considerations as well as social demand are all drivers for involving the public in decisions about their participation in screening.

- Our findings suggest that providing women with more balanced information on the risks as well as the benefits of screening would not undermine the national screening programme.

- Given the paucity of relevant trials, our findings are important in triggering further research. Further studies are needed to confirm our findings, using actual attendance as an outcome.

\section{Findings in relation to other studies}

A few studies have investigated the effects of offering different types of information on intended ${ }^{2426}$ or actual uptake ${ }^{27} 28$ of screening. Providing more information increases knowledge and assists in decision making, ${ }^{29}$ but has an unpredictable effect on uptake. ${ }^{30}$ In three studies assessing the effect of information giving on decisions to undergo screening for prostate cancer, two found that intervention reduced uptake, while in the other there was no effect. ${ }^{29}$ In a study to assess willingness to undergo screening for pancreatic cancer, participants who were given extended information were significantly less likely to accept the test compared with those given basic information. ${ }^{24}$ However, in a trial of women at low to moderate risk of breast cancer, better information had no effect on wanting to have genetic screening. ${ }^{27}$ Decisions on screening are not just influenced by the information provided, but also by other factors, such as values, cultural beliefs, and personal experiences. ${ }^{30}$ Indeed, we found a tendency for women who had personal contact with someone with cancer to be more likely to want to undergo screening.

\section{Unanswered questions and future research}

Our intervention leaflet offered evidence based information related to the topics emphasised by the GMC. However, we do not know whether this contained sufficient information for decision making and whether it included messages, that women who have been through the process themselves, would feel are important. Furthermore, although there is some evidence that the medium used to convey information has little effect on knowledge, understanding, or decision making, ${ }^{30}$ little is known about the most effective form of presentation.

\section{Conclusions}

Our findings suggest that providing women with a more balanced appraisal of the pros and cons of screening, as well as being more ethical, would result in a reduction in screening uptake, though our point estimate suggests that uptake rates would not be much below the current target rate of $80 \%$. Furthermore, we found no evidence that information would adversely affect women at higher risk.

\section{ACKNOWLEDGEMENTS}

We thank all the staff at Cofton Medical Centre (Longbridge), Jiggin's Lane Practice (Bartley Green), and Shanklin House Surgery (Handsworth) for their cooperation during this study. We also thank Dr Paul Aveyard for his help with some of the analysis.

\section{Contributors}

PA conceived the idea for the project, supervised it, and wrote the final paper. BR, HS, and NB developed the project, carried out the data collection, collation and initial analysis, and wrote the first draft. TM and AR were involved in initial discussions on the project and in developing the hypothesis, calculated the population effects of cervical screening, and provided this for the information leaflets used, and have contributed to the final draft.

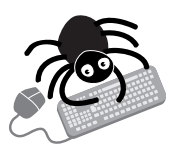

A copy of the intervention leaflet used in the study is available on the journal web site (www.jech.com/supplemental)

Authors' affiliations

P Adab, T Marshall, A Rouse, Department of Public Health and Epidemiology, University of Birmingham, Edgbaston, Birmingham, UK B Randhawa, H Sangha, N Bhangoo, School of Medicine, University of Birmingham

\section{REFERENCES}

1 Department of Health. Cervical screening programme, England 1999-2000. London: Department of Health, 2000. [Available from Department of Health, PO Box 777 , London SE 1 6XH].

2 National Office of the NHS Cervical Screening Programme. About the NHS Cervical screening programme. http:// www.cancerscreening.nhs.uk/cervical/index.html\#cost. NHS Cervical Screening Programme, 2000. (Accessed 5 Oct 2002).

3 Sasieni P, Adams J. Effect of screening on cervical cancer mortality in England and Wales: analysis of trends with an age period cohort model. BMW 1999;318:1244-5.

4 Austoker J. Cancer prevention in primary care. Screening for cervical cancer. BM 1994;309:241-8.

5 Quinn $M$, Babb P, Jones J, et al. Effect of screening on incidence of and mortality from cancer of cervix in England: evaluation based on routinely collected statistics. BM 1999;318:904-8.

6 Raffle AE, Alden B, Mackenzie EF. Detection rates for abnormal cervical smears: what are we screening for? Lancet 1995;345:1469-73.

7 Cannistra SA, Niloff JM. Cancer of the uterine cervix. N Engl J Med 1996;334:1030-8

8 Cockburn J, Redman S, Hill D, et al. Public understanding of medical screening. J Med Screen 1995;2:224-7.

9 NHS Cervical Screening Programme. Report of the first five years of the NHS cervical screening programme. London: NHSCSP, 1994.

10 Coulter A. Evidence based patient information. is important, so there needs to be a national strategy to ensure it. BM 1998;317:225-6.

11 Foster P, Anderson CM. Reaching targets in the national cervical screening programme: are current practices unethical? J Med Ethics 1998;24:151-7.

12 Anonymous. Double jeopardy for women in cervical screening. Lancet 1999;354:1833

13 General Medical Council. Seeking patients' consent: the ethical considerations. London: General Medical Council, 1999.

14 Rouse A, Marshall T. Are you obtaining proper consent for smear tests? Pulse 2000; 13 May:60

15 Nottingham J. Women must be given fully informed information about cervical screening. BM 1999;318:1555-6.

16 Davey C, Austoker J, Jansen C. Improving written information for women about cervical screening: evidence based criteria for the content of letters and leaflets. Health Education Journal 1998;57:263-81.

17 Raffle AE. Screening for the 21 st century: learning from the past. Cytopathology 2000;1 1:4-7

18 Kreuter MW. Dealing with competing and conflicting risks in cancer communication. I Natl Cancer Inst Monogaphs 1999:25:27-35.

19 Robinson A, Thomson R. Variability in patient preferences for participating in medical decision making: implication for the use of decision support tools. Qual Health Care 2001;10:34-8.

20 Stewart-Brown S. Can it be ethical to run a screening programme under false pretences? Pulse 1997:57:87-9.

21 Anderson CM, Nottingham J. Bridging the knowledge gap and communicating uncertainties for informed consent in cervical cytology screening; we need unbiased information and a culture change. Cytopathology 1999;10:221-8.

22 NHS Cervical Screening Programme and Cancer Research Campaign. Your smear test. London: Health Education Authority, 1996. 
23 Wolf AM, Philbrick JT, Schorling JB. Predictors of interest in prostate-specific antigen screening and the impact of informed consent: what should we tell our patients? Am J Med 1997;103:308-14.

24 Domenighetti G, Grilli R, Maggi JR. Does provision of an evidence-based information change public willingness to accept screening tests? Health Expectations $2001 ; 3: 145-50$.

25 Edwards A, Elwyn G, Mulley A. Explaining risks: turning numerical data into meaningful pictures. BM 2002;324:827-30.

26 Wolf AM, Nasser JF, Schorling, JB. The impact of informed consent on patient interest in prostate-specific antigen screening. Arch Intern Med 1996;156:1333-6
27 Lerman C, Biesecker B, Benkendorf IL, et al. Controlled trial of pretest education approaches to enhance informed decision-making for BRCA 1 education approaches to enhance informed decision-

gene testing. J Natl Cancer Inst 1997;89:148-57.
28 Flood AB, Wennberg JE, Nease RFJ, et al. The importance of patient preference in the decision to screen for prostate cancer. Prostate Patient Outcomes Research Team. J Gen Intern Med 1996;1 1:342-9.

29 O'Connor AM, Rostom A, Fiset V, et al. Decision aids for patients facing health treatment or screening decisions: systematic review. BMJ 1999;319:731-4.

30 Jepson R, Forbes C, Sowden A, et al. Increasing informed uptake and non-uptake of screening: evidence from a systematic review. Health Expectations 2001;4:116-30.

\section{SPEAKER'S CORNER}

\section{Health, equity, human rights, and the invasion of Iraq}

D uring the days culminating in the US-British invasion of Iraq, I was working with a human rights attorney colleague, exploring links and distinctions between health, equity, and human rights. These concepts thus have been in my thoughts, and concern for each leads me to deplore the invasion of Iraq on several counts.

Firstly, given the scale of suffering and death that inevitably accompany war, it is unconscionable to embark on that course, even for a just cause, except as a clearly demonstrated last resort. There is widespread international consensus that reasonable alternatives to war had not been exhausted in this case. The consequences of war include not only its direct effects but the massive aftershocks resulting from destruction of infrastructure (for example, clean water) critical for survival and health; many more deaths occurred for this reason in the wake of the first Gulf War than as a direct result of the military action itself. Moreover, this is not a just war; evidence linking Iraq and September 11 or Al Qaeda was never produced, and equally heinous regimes have been tolerated or supported (as Saddam Hussein was previously) by the US. There are many reasons to suspect that the real motives for US interest in a regime change in Iraq have more to do with control of oil and empire than with fighting terrorism. Terrorism will surely increase in light of the hatred this war and the ensuing occupation will provoke for generations to come, throughout the Arab and Islamic worlds and among others who reject the disturbing vision of a hegemonic New World Order evoked by this invasion.

Secondly, by setting the frightening dual precedents of preemptive military strikes and defiance of the United
Nations, this action drags the entire world backward toward the laws of the jungle, obliterating decades of work toward global disarmament and 50 to 100 years of work toward international governance. The arrogance this reflects is in itself shocking.

Thirdly, this war will exacerbate inequities. In Iraq, it undoubtedly is now taking and will continue in its aftermath to take its heaviest toll on the poor and especially poor children. In the US, the costs of the war and its aftermath most certainly will accelerate the dismantling of public services already started by the current administration's domestic policies, thereby increasing social disparities in this country; and there will be less support for international development outside the self serving agenda for the Fertile Crescent.

Fourthly and finally, this action represents a grave threat to human rights globally. By its explicit undermining of the authority of the United Nations (UN), the Bush administration has implicitly undermined the force of international law overall and specifically of human rights treaties and other agreements developed under UN auspices. We must publicly condemn this unjustified war, find ways to help repair the damage, and develop new strategies to struggle for health, equity, and human rights in a world that is far more brutal and violent than the world we had dared hope to encounter in the 21 st century.

P A Braveman

Center on Social Disparities in Health, Box 0900, Univ of CA, SF San Francisco, USA; pbrave@itsa.ucsf.edu 